\title{
Analysis of United Kingdom offshore wind farm performance using public data: improving the evidence base for policy development.
}

ALDERSEY-WILLIAMS, J., BROADBENT, I.D., STRACHAN, P.A. 
Analysing the Performance of United Kingdom (UK) Offshore Wind Farms Using Public Data: Improving the Evidence Base for Policy Development

John Aldersey-Williams, Ian D. Broadbent and Peter A. Strachan

j.aldersey-williams@rgu.ac.uk

Aberdeen Business School

Robert Gordon University

Garthdee Road

Aberdeen

AB10 7QE

Scotland

United Kingdom

\begin{abstract}
Policymakers increasingly need to balance the requirements of energy demand, security and costs: they need accurate estimates of performance. This paper uses public data to assess UK offshore wind farm performance to improve policy decisions. It finds that average capacity factors have improved from $34.9 \%$ in Round 1 to $41.0 \%$ in Round 2 projects. Drivers for performance are examined and the correlations in performance between UK offshore wind farms analysed. The paper also addresses problems with existing capacity factor estimates and generates new estimates of inter-year variability of capacity factor, providing a more accurate evidence base for policy decisions.

1 Introduction

Increasing worldwide demand for zero-carbon energy has driven rapid growth in the deployment of offshore wind. The first offshore turbines were installed in Vindeby in Denmark in 1991, leading the way for deployment in many other countries in Europe, including the United Kingdom, and in Asia and the United States [1].
\end{abstract}


As of June 2018, the total operational offshore wind capacity in UK waters was just over 7,000 MW[2] out of a worldwide total of just under 17,000 MW [2].

Offshore wind around the world has been supported by a range of financial and other support schemes, including Feed-In Tariffs (FIT) and green certificate schemes (also known as renewable portfolio standards or "market based" schemes) [3]. In the United Kingdom, support for offshore wind evolved from Feed-In Tariffs (the Non-Fossil Fuel Orders) to the Renewable Obligation and then back to Feed-In Tariffs under the new Contract for Difference regime [4]. There is a considerable literature on the relative merits of these support strategies (e.g. ) [3],[5-9] ); this paper does not seek to add to that work.

However, accurate data on the technical performance of offshore wind farms is of importance to policymakers who formulate, implement and monitor support schemes. Some support schemes require operators to publish detailed performance on the output of the offshore wind farms supported by those schemes. This paper uses that data, adopting an approach outlined by the Renewable Energy Foundation [10] and applied by Staffell and Green [11], and Crabtree et al. [12], to derive important lessons on the real world performance of offshore wind farms, the inter- and intra-year variability of output, the correlations between performance of wind farms based on their location, and what this data might tell observers about wind farm value, reliability and availability.

This paper is set out in 5 sections. Section 1 introduced the main themes. Section 2 briefly summarises the development of offshore wind in the UK and describes the source of data used in this review. Section 3 sets out the methodology adopted in extracting performance information from the Renewable Obligation Certificate ('ROC') register and combining this with other information to determine month by month capacity factor.

Section 4 sets out the results of the analysis to show average capacity factors, their annual and monthly variation, and considers the drivers for increased capacity factors as new wind farms are deployed. Section 5 discusses these results and the implications of this approach for project developers and policy-makers alike. 


\subsection{Development of capacity}

The first offshore wind turbines in UK waters were installed at Blyth in Northumberland in 2000 and operated until 2013 [13]. The first commercial offshore wind farms, Scroby Sands and North Hoyle, located off Great Yarmouth and Rhyl respectively, have been in operation since 2004 [2] .

With minor exceptions, the deployment of offshore wind in the UK was arranged in a number of "rounds", administered by the Crown Estate on behalf of the UK and Scottish Governments [14]. Round 1, in 2001, included 16 sites, each limited to a maximum of 30 turbines (although there was one double site - Robin

Rigg - and one triple site - Cirrus Array). Round 1 aimed to demonstrate the commercial applicability of the technology whilst limiting the total cost of revenue support. As available turbines were limited to around $3 \mathrm{MW}$ in capacity at this time, the typical capacity of Round 1 windfarms was around 70-100 MW [14].

As of 2018, 13 of these sites had been developed, with a total capacity of $1.2 \mathrm{GW}$. A number of sites were offered for lease but were not developed, for technical, environmental or commercial reasons, and two of these Round 1 sites - Blyth and Beatrice Demonstrator - are no longer in operation [14].

Round 2, which offered sites up to $900 \mathrm{MW}$, followed in 2002. Round 2 sites were typically further from shore and were sized for significantly larger projects. Seventeen sites were offered, of which 14 have now been commissioned, with the other three not progressing to development. The total installed capacity in Round 2 is $4.8 \mathrm{GW}[14]$.

The Scottish Territorial Waters ("STW") round in 2009 offered applicants the opportunity to define their desired development sites. This was a change from Round 1 and Round 2, where the Crown Estate defined the sites on offer. The STW round was for projects similar in scale to the Round 2 projects, and three conventional, fixed foundation projects totalling 1.8 GW have progressed to development (Beatrice, Inch Cape and Neart na Gaoithe), with Beatrice being commissioned in July 2019 [15].

In 2009, a number of extensions to Round 1 and Round 2 projects were also permitted, with an additional capacity of $1.3 \mathrm{GW}$ now operational [14].

The most recent round, Round 3, involved much larger sites, many of which were much further from shore than those in earlier rounds. A total of $20 \mathrm{GW}$ was approved under Round 3, and the first project (Rampion, $400 \mathrm{MW}$ ) is now becoming operational [14]. 
In addition, two floating wind farms have begun production: the Equinor (formerly Statoil) HyWind project, which demonstrated floating wind at limited scale (5 turbines, $30 \mathrm{MW}$ ) [14], and the Kincardine project, which began generation from a single $2 \mathrm{MW}$ turbine in late 2018 but has a total planned capacity of $50 \mathrm{MW}$ [15]. Finally, two demonstration/test sites have been permitted: the European Offshore Wind Deployment Centre (93 MW), offshore Aberdeen, began production in early 2018, and the Blyth Offshore Wind Demonstrator (41.5 MW), offshore Northumberland, is under construction.

\subsection{Development of support policies}

The UK Government has adopted a number of different support policies over time. The Non-Fossil Fuel Orders ('NFFO'), which began in 1990, encouraged small scale development of renewables. They were replaced in 2002 by the Renewables Obligation and the Renewables Obligation (Scotland)('RO') [16]. The RO placed an obligation on licensed electricity suppliers to source a defined percentage of their electricity from renewable sources, or to pay a penalty [17]. Compliance with the Obligation is demonstrated by the submission of ROCs which are allotted to ROC-registered renewable generators.

As the cost of the RO increased in response to rapid growth in renewable capacity, the Government implemented Electricity Market Reform ('EMR') to control the costs of supporting these technologies. Following the Government's EMR programme in 2011, the RO was closed to new applications, and after a period of transitional arrangements, new offshore wind farms became eligible to compete for a new type of financial support under Contracts for Difference [18].

This paper does not consider the effectiveness of these support schemes, but notes that wind farm operators (and operators of other renewables projects) are required to submit monthly operational data to the regulator OFGEM (the Office of Gas and Electricity Markets), which publishes this data in its ROC Register [13]. This data is publicly available and provides a rich source of information on the detailed operational performance of many UK wind farms. It comprises two main sources of performance data: ROCs and Renewable Energy Guarantee of Origin (REGO) certificates.

This analysis uses the ROC data, as this covers almost all of the offshore wind farms operational in the UK at present. 
As a consequence of support offered under the RO, the UK now has the largest operational capacity of offshore wind energy in the world. Against this background, the next section considers what might be learned from the performance of this large offshore wind fleet.

3 Capacity factor-importance and measurement methodology

\subsection{Importance of capacity factor}

The capacity factor, defined as the actual output divided by the nameplate capacity of a wind farm, is a critical measure of operating performance, and hence economic value, for wind farms [19]. It is influenced by the wind speed conditions, the turbine power curve, wind farm wake effects and the availability of the turbines (the percentage of the time that they are available to generate, and not unavailable due to maintenance or unplanned outage) [20].

A number of authors [20-25] have estimated theoretical capacity factors by combining wind speed data with turbine power curves provided by OEMs. Masters [26] derived and Jacobson and Masters [27] applied a simpler formula in which annual energy production is given by $\mathrm{P} * 8760 *\left(0.087 \mathrm{~V}-\mathrm{P} / \mathrm{D}^{2}\right)^{1}$. Although capacity factors calculated in this way offer valuable insights into total resource potential and outline economics, they do not include any assessment of the impact of downtime, maintenance outages or wake effects on aggregated wind farm output.

A recent paper by Carroll et al. found that offshore wind turbine availability can reach $91.6-93.5 \%$ for nearshore turbines with good maintenance arrangements, although this can fall abruptly with distance from shore (due to difficulties in accessing turbines) [28].

Although capacity factor is a critical determinant of the economic performance of offshore wind (and other renewables) projects, there is little in the literature on actual capacity factors, and nothing on its inter- and intra-year variability. Staffell and Green [11], and Crabtree et al., [12] applied a method described by the Renewable Energy Foundation [10] to determine capacity factors for UK wind farms from published performance-based information although Staffell and Green limited their analysis to onshore projects.

\footnotetext{
${ }^{1} \mathrm{P}=$ power in $\mathrm{kW} ; \mathrm{D}=$ rotor diameter in metres. This formula calculates a wind turbine's power as a simple linear function of wind speed with a minimum wind speed cut-in defined as a function of $P / D^{2}$, implicitly assuming that the wind turbine operates within the linear region of its power curve. Analysis of the effectiveness and accuracy of this elegant simplified formula is outside the scope of this paper.
} 
Crabtree et al. considered offshore wind farms, using data from commissioning to June 2014 and found that on average Round 2 projects outperformed the smaller and earlier Round 1 projects.

This paper adopts the same approach, using data from commissioning until April 2018, and extends that analysis to evaluate inter-year and intra-year variability of performance, and performance correlations between wind farms.

These estimates are important for meaningful valuation and provide insight into wind farm reliability and the correlations in performance between wind farms based on their geographic locations.

\subsection{Methodology}

OFGEM's Renewables Register provides data on wind farm performance on a month by month basis [13]. Analysis of this raw data can offer broadly applicable insights into actual capacity factors achieved by offshore wind farms (as distinct from estimated capacity factors derived from turbine power curves, wake effect modelling and actual or predicted wind speed information). These actual capacity factors can offer some insight into wind farm operational performance and therefore into the value of these projects.

OFGEM's ROC Register is available on the internet [13] and can be interrogated to provide information on the numbers of ROCs allotted to each ROC-eligible project in each month.

The analysis in this paper is based on ROC data, rather than REGO data, as the early years data has a higher resolution, and virtually all of the operational offshore wind farms in the UK are ROC-accredited. As this analytical approach is applied in future, in a context where more non-ROC wind farms are operational, it may be best to combine data from ROCs and REGOs to provide the richest possible dataset.

Monthly ROC data and nameplate capacity for each of these projects has been extracted from the ROC Register [13]. The OFGEM Register includes a figure for the number of MWh per certificate, based on the RO Banding rules in force during each reporting period, allowing conversion of the number of certificates to the power generated in MWh for each month. This latter figure is then divided by the nameplate capacity and the correct number of hours for the month under consideration to produce a monthly project capacity factor.

The same approach could also be applied to any other technologies which have achieved ROC accreditation, including onshore wind, biomass and even wave and tidal stream, and the same analysis applied to REGOs can extend this technique to non ROC-accredited projects.

The equation setting out the calculation of monthly capacity factor is set out in equation 1 below. 


$$
C F_{i}=\frac{E_{i}}{C \cdot h i}
$$

$i=$ time interval index

$\mathrm{CF}_{\mathrm{i}}=$ capacity factor for the period

$E_{i}=$ total energy generated in period, in MWh

$\mathrm{C}=$ nameplate capacity in MW

$\mathrm{h}_{\mathrm{i}}=$ number of hours in month

4 Analysis - capacity factors and output variability

These data have been analysed at a number of levels of detail, to extract insights as the variability of wind farm performance.

\subsection{Capacity factor}

The first analysis determines average capacity factor since commissioning and for the most recent available 12 months (August 2017-July 2018). This analysis is summarised in Table 1. Projects have been assigned to Round 1 or Round 2 according to the Round in which they were awarded, with the proviso that Kentish Flats Extension, which was in the 2010 Round 1 and 2 Extensions Round is considered to be in Round 2, and are shown in the table in order of commissioning date.

\begin{tabular}{|c|c|c|c|c|c|c|c|}
\hline Name & $\begin{array}{l}\text { Start- } \\
\text { up }\end{array}$ & $\begin{array}{l}\text { Capacity } \\
\text { (MW) }\end{array}$ & Round & $\begin{array}{l}\text { Average } \\
\text { monthly } \\
\text { capacity } \\
\text { factor } \\
(\%, \text { since } \\
\text { startup) }\end{array}$ & $\begin{array}{c}\text { Capacity } \\
\text { factor (\%, } \\
\text { last } 12 \\
\text { months } \\
\text { only) }\end{array}$ & $\begin{array}{c}\text { Standard } \\
\text { deviation of } \\
\text { annual } \\
\text { capacity } \\
\text { factor }\end{array}$ & $\begin{array}{l}\text { Reported } \\
\text { months }\end{array}$ \\
\hline \multicolumn{8}{|l|}{ Round 1 projects } \\
\hline $\begin{array}{l}\text { North Hoyle Offshore } \\
\text { Wind Farm - A }\end{array}$ & 2004 & 60.0 & 1 & $34.1 \%$ & $32.6 \%$ & $3.0 \%$ & 170 \\
\hline
\end{tabular}




\begin{tabular}{|c|c|c|c|c|c|c|c|}
\hline $\begin{array}{l}\text { Scroby Sands Wind } \\
\text { Farm }\end{array}$ & 2005 & 60.0 & 1 & $31.0 \%$ & $33.5 \%$ & $2.5 \%$ & 156 \\
\hline $\begin{array}{l}\text { Barrow Offshore } \\
\text { Windfarm - A }\end{array}$ & 2006 & 90.0 & 1 & $36.2 \%$ & $36.2 \%$ & $4.7 \%$ & 142 \\
\hline Kentish Flats Ltd - A,C & 2006 & 90.0 & 1 & $31.4 \%$ & $30.2 \%$ & $3.2 \%$ & 151 \\
\hline $\begin{array}{l}\text { Burbo Offshore } \\
\text { Windfarm }\end{array}$ & 2007 & 90.0 & 1 & $34.1 \%$ & $26.0 \%$ & $4.1 \%$ & 129 \\
\hline $\begin{array}{l}\text { Inner Dowsing Offshore } \\
\text { Wind Farm }\end{array}$ & 2008 & 90.0 & 1 & $34.4 \%$ & $36.1 \%$ & $3.5 \%$ & 112 \\
\hline $\begin{array}{l}\text { Lynn Offshore Wind } \\
\text { Farm }\end{array}$ & 2008 & 90.0 & 1 & $34.6 \%$ & $36.2 \%$ & $2.3 \%$ & 112 \\
\hline Gunfleet Sands I & 2009 & 198.0 & 1 & $35.1 \%$ & $35.0 \%$ & $1.7 \%$ & 97 \\
\hline Rhyl Flats Wind farm & 2009 & 90.0 & 1 & $35.8 \%$ & $34.4 \%$ & $2.5 \%$ & 103 \\
\hline $\begin{array}{l}\text { Robin Rigg Offshore } \\
\text { Wind Farm (West) }\end{array}$ & 2009 & 89.2 & 1 & $35.5 \%$ & $36.3 \%$ & $2.0 \%$ & 94 \\
\hline $\begin{array}{l}\text { Robin Rigg Offshore } \\
\text { Wind Farm (East) }\end{array}$ & 2010 & 83.3 & 1 & $35.1 \%$ & $34.5 \%$ & $2.0 \%$ & 94 \\
\hline Ormonde Wind Farm & 2011 & 148.0 & 1 & $38.7 \%$ & $32.1 \%$ & $4.6 \%$ & 77 \\
\hline Teesside windfarm & 2013 & 61.1 & 1 & $37.0 \%$ & $36.0 \%$ & $2.2 \%$ & 51 \\
\hline \multicolumn{8}{|l|}{ Round 2 projects } \\
\hline Gunfleet Sands II & 2009 & 64.8 & 2 & $36.6 \%$ & $36.9 \%$ & $2.0 \%$ & 97 \\
\hline $\begin{array}{l}\text { Thanet Offshore Wind } \\
\text { Farm }\end{array}$ & 2010 & 298.0 & 2 & $32.3 \%$ & $32.6 \%$ & $1.8 \%$ & 94 \\
\hline Greater Gabbard & 2011 & 504.0 & 2 & $42.1 \%$ & $41.2 \%$ & $2.2 \%$ & 59 \\
\hline Sheringham Shoal & 2011 & 315.0 & 2 & $39.9 \%$ & $40.5 \%$ & $2.0 \%$ & 63 \\
\hline $\begin{array}{l}\text { Walney Offshore Wind } \\
\text { Phase I }\end{array}$ & 2011 & 182.0 & 2 & $40.6 \%$ & $40.2 \%$ & $2.6 \%$ & 84 \\
\hline $\begin{array}{l}\text { Walney Offshore Wind } \\
\text { Phase II }\end{array}$ & 2011 & 182.0 & 2 & $44.8 \%$ & $45.6 \%$ & $7.8 \%$ & 73 \\
\hline
\end{tabular}




\begin{tabular}{|l|c|c|c|c|c|c|c|}
\hline Lincs Wind Farm & 2012 & 256.0 & 2 & $41.5 \%$ & $42.2 \%$ & $2.6 \%$ & 58 \\
\hline London Array Offshore & 2012 & 625.8 & 2 & $41.6 \%$ & $40.5 \%$ & $2.4 \%$ & 63 \\
\hline Windfarm & 2013 & 570.2 & 2 & $35.1 \%$ & $36.5 \%$ & $5.2 \%$ & 37 \\
\hline West of Duddon Sands & 2014 & 374.0 & 2 & $45.0 \%$ & $45.2 \%$ & $3.0 \%$ & 45 \\
\hline Offshore Wind Farm & 2014 & 205.0 & 2 & $47.5 \%$ & $49.4 \%$ & $3.5 \%$ & 38 \\
\hline Westermost Rough \\
Humber Gateway
\end{tabular}

Table 1: Wind farms included in study and capacity factors (authors' analysis). N.B. Standard deviation is for the annual capacity factors, which are themselves calculated as the average of the monthly capacity factors for the year concerned.

In almost all cases, the performance over the last 12 months is broadly comparable with the full life average, suggesting that this recent period was typical in its wind resource. The exception was Burbo Bank: a review of the monthly ROC data shows no production in October and very reduced production in November 2017. 4C Offshore [15] reported maintenance activity on two turbines in November, supporting an inference of a reliability issue with the wind farm over this period.

Crabtree et al. [12] compared the capacity factors of wind farms from Round 1 and Round 2, using average capacity factor since commissioning. They found that Round 1 projects underperformed Round 2 projects, with average capacity factors of 33.6\% (Standard Error on the Mean (SEM): $0.6 \%$ ) and 38.3\% (SEM: $1.0 \%$ ) respectively.

It should be noted that comparison of capacity factor between Rounds 1 and 2 must be undertaken with care. If full life data is used, this inevitably samples longer data series for Round 1 projects, and the apparent relative performance of Round 1 and 2 projects might in fact be a reflection of a more general variability in the wind climate. Put simply, if the more recent years were windier, the Round 2 projects would appear better than older Round 1 projects, simply because their time series data sampled a windier regime.

A brief review of UK annual average wind speed data [29], suggests that there has been no strong trend in wind resource in the UK since 2001. However, wind turbine performance is highly responsive to short term 
wind speed fluctuations, and these are not adequately captured in monthly average data. Further work should be undertaken to explore the inter-year variability of the UK wind resource to inform this comparative analysis better.

This new analysis draws on some 43 additional months of performance data and addresses the concern with Crabtree et al.'s methodology by ensuring that the projects were evaluated in the same wind conditions.

This new analysis supports and even extends Crabtree et al.'s analysis, and finds that the Round 1 average capacity factor over this period was $34.9 \%$ (SEM: $2.0 \%$ ) and that for Round 2 was $41.0 \%$, (SEM: $2.8 \%$ ) where their data showed an average capacity factor for Round 1 of $33.6 \%$ against Round 2 projects' average of $38.3 \%$. These findings suggest that the most recent 12 months had a marginally better wind resource the period in the Crabtree review, but found a similar disparity between Round 1 and Round 2 projects.

These findings are consistent with the BEIS Electricity Generation Costs report [30] which assumes a capacity factor of $42 \%$ in estimating Levelised Cost of Energy (LCOE) for Round 2 offshore wind farms.

The standard deviation of the life time average capacity factor for these wind farms has also been calculated. It is found that it is $2.0 \%$ for Round 1 farms, and $4.1 \%$ for Round 2 projects. If the Walney 2 project, which has an anomalously high variability in its capacity factor, is excluded, the standard deviation for Round 2 projects falls to $2.8 \%$. The OFGEM Register reveals that Walney 2 had an extended outage in early 2016, and this clearly contributes to this anomalously high variability in capacity factor.

A statistical two-sample t-test has been applied, using these mean and standard deviation calculations, and the sample sizes of 13 for each population of wind farms. The t-test yields a result of 4.7, making the result highly statistically significant. Put more simply, it can be confidently stated that typical capacity factors for Round 2 wind farms are higher than those for the older Round 1 wind farms.

If this trend were to continue into Round 3, where wind farms are expecting to deploy larger turbines, further offshore and in deeper water, a further increase in capacity factors from Round 2 levels might be expected.

\subsection{Drivers of capacity factor}

These initial findings support the general expectation that larger, more modern wind farms should achieve higher capacity factors than smaller ones. This is expectation is based on both turbine size and wind resource considerations: newer wind farms typically deploy larger turbine sizes, which are both better at capturing 
energy from the wind and encounter higher wind speeds due to their higher hub heights); and larger wind farms are typically deployed further from shore, where wind resource can be better.

To test these ideas, the average annual capacity factors over the full life of each project determined here have been correlated by linear regression analysis against commissioning date, wind farm capacity, turbine capacity, distance from shore, water depth and latitude (as increased northerliness might be expected to correlate with increased wind resource). The data on commissioning date, wind farm capacity and turbine capacity, distance offshore, latitude and water depth have been taken from the 4C Offshore online database $[15]$.

The variables of commissioning date, wind farm capacity and turbine capacity are used as proxies for the effect of technological improvement, while the distance from shore, latitude and water depth are proxies for the geographical variability of wind resource.

A multiple linear regression of capacity factor and these variables. It shows that only commissioning date has a significant correlation with capacity factor, with no significant correlation for the other variables. This analysis found that the " R Squared" for the multiple regression was $49.3 \%$, and a simple linear regression of capacity factor against commissioning date returned an R Squared value of $32.8 \%$, reinforcing the point that commissioning date was the only variable with a significant effect on capacity factor. Although not statistically significant, the R Squared value for the correlation of water depth with capacity factor was $28.2 \%$

These correlations suggest that technological improvement is a driver of capacity factor, although the very weak correlation with turbine capacity suggests that it is not simply capacity which drives improved performance, perhaps indicating improved efficiency - through better blade design and generator efficiency is more important.

The correlation of capacity factor with water depth (as a surrogate for wind resource) confirms that better performance comes with distance offshore, showing that the wind resource is important.

This evaluation supports the general view that larger turbines, in deeper water can be expected to perform at higher capacity factors than their nearshore, smaller predecessors. 


\subsection{Overall trend in capacity factors}

Staffell and Green [11] undertook an analysis of onshore wind farm performance degradation with age, comparing output performance from ROC data with expected performance from wind resource data, and found that the average capacity factor declined by some $1.6 \%$ per annum in onshore turbines. If this were true for offshore wind projects this would suggest that a capacity factor of $40 \%$ would decline to $34 \%$ over a decade of operation.

It is observed in this review that the capacity factors for Barrow, Kentish Flats, North Hoyle and Scroby Sands - which have all been operational for more than 10 years - have stayed broadly constant or increased slightly over the period (Figure 1), suggesting that either offshore wind farms are not subject to the same degradation, or that the wind climate has improved.

As it seems unlikely that offshore wind farms are not subject to similar performance degradation as onshore wind farms, this finding is worthy of additional research. Such work should apply Staffell and Green's methodology to offshore wind data, determine whether similar performance degradation in offshore projects has been masked by increasing wind resource, or if better maintenance in offshore projects mitigates the observed degradation.

\subsection{Inter-year capacity factor variability}

The analysis of ROC data can provide useful information on inter-year variability in performance. The standard deviation for the annual average capacity factor is shown for each project in Table 1 . This shows that the typical variability as measured by standard deviation of the annual average capacity factor is between $2 \%$ and $3 \%$, which we hypothesise is driven by variability in wind speeds between years. The higher variability of some projects, notably Walney Phase 2 , is explained by periods of operational nonperformance at these wind farms. The analysis of inter-year variability and correlation with wind speeds is beyond the scope of this paper, but would be an interesting follow-up.

\subsubsection{Focus on Barrow, Kentish Flats, North Hoyle and Scroby Sands}

This section focusses on the four wind farms, Barrow, Kentish Flats, North Hoyle and Scroby Sands which have been in operation for a decade or more. The annual average capacity factor for these projects provides insights into the inter-year variability of wind farm performance and into general trends in wind climate. 


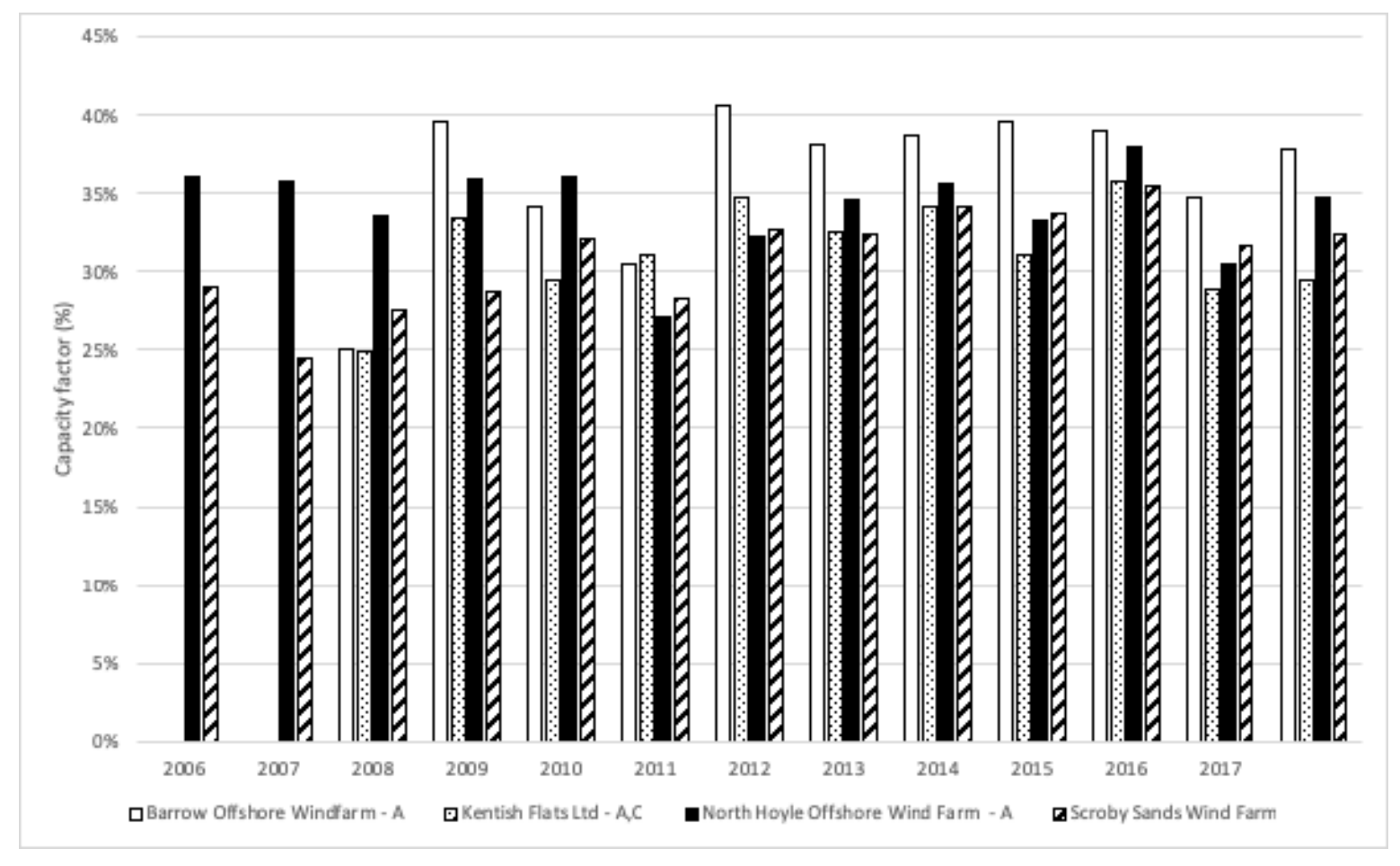

Figure 1: Annual average capacity factor (authors' analysis)

Figure 1 shows the average annual capacity for these four wind farms. Analysis of these data can provide insights into the inter-year variability of wind farm performance, which is important when a probabilistic approach is adopted in evaluating LCOE, and into the overall trend in wind farm performance (which is itself a function of the wind climate and the wind farms' performance).

A linear regression analysis of capacity factor with year of production has been undertaken to identify whether any trends are apparent in these capacity factors. It finds that although three of the four wind farms show an increase in annual average capacity factor, there is only a reasonable correlation coefficient in the case of Scroby Sands.

\begin{tabular}{|l|l|l|l|}
\hline Wind farm & $\begin{array}{l}\text { Standard deviation of } \\
\text { annual average capacity } \\
\text { factor (\%) }\end{array}$ & $\begin{array}{l}\text { Annual increase in } \\
\text { capacity factor (best fit) } \\
(\mathbf{\%})\end{array}$ & $\begin{array}{l}\text { Coefficient of } \\
\text { determination }\left(\mathbf{r}^{\mathbf{2}}\right) \text { for } \\
\text { best fit capacity } \\
\text { factor }(\%)\end{array}$ \\
\hline Barrow & $4.7 \%$ & $0.7 \%$ & $23 \%$ \\
\hline Kentish Flats & $3.2 \%$ & $0.2 \%$ & $5 \%$ \\
\hline North Hoyle & $2.9 \%$ & $-0.1 \%$ & $2 \%$ \\
\hline
\end{tabular}




\begin{tabular}{|l|l|l|l|}
\hline Scroby Sands & $3.2 \%$ & $0.7 \%$ & $59 \%$ \\
\hline
\end{tabular}

These "best-fit" regressions suggest that the overall trend in capacity factor is not strongly positive or negative. If Staffell and Green's findings of a performance degradation are valid for offshore projects, this would suggest an equal and opposite improvement in wind climate over the period. Further research extending Staffell and Green's approach offshore would be valuable.

\subsubsection{Impact of capacity factor on Monte Carlo evaluation of LCOE}

The comparative costs of energy generation alternatives are important in informing policy decisions, and there is a considerable body of literature addressing this [31-34]. Some of this literature proposes the use of probabilistic "Monte Carlo" approaches to this evaluation, most notably Heck et al. [31] and Cartelle Barros et al. [34]. This approach requires ranges to be defined for input variables, and these authors stated ranges for capacity factor for wind from $22.75 \%-59.75 \%$ [31] and 25\%-35\% [34] but did not justify these ranges.

This analysis finds that a mean value for capacity factor of $41 \%$ is appropriate for UK Round 2 wind farms, and a range of 2 standard deviations encompassing $95 \%$ of likely values defines a range from $35-47 \%$. The use of this new, better informed data should lead to better probabilistic estimates of costs of energy and should be used as a basis for such estimates in future.

\subsection{Intra-year capacity factor variability}

Variability of capacity factor within each year is driven by wind conditions and wind farm availability. The capacity factor can be expected to correlate fairly strongly across the entire wind farm fleet, and especially within geographically localised areas, whereas availability is entirely endogenous to each wind farm.

The OFGEM Register-derived data allows for the variability within each year for each wind farm to be analysed. As has been shown in the previous section, inter-year variability is relatively low. However, variability within the year, as perhaps would be expected in a temperate marine climate like that of the UK, is high.

North Hoyle has been selected for analysis, as it offers the longest time-series data. It should be noted that in June 2010 the North Hoyle wind farm had a very low capacity of some 4.3\%, which we speculate was due to a maintenance-related outage. This anomaly does not significantly affect these results. 


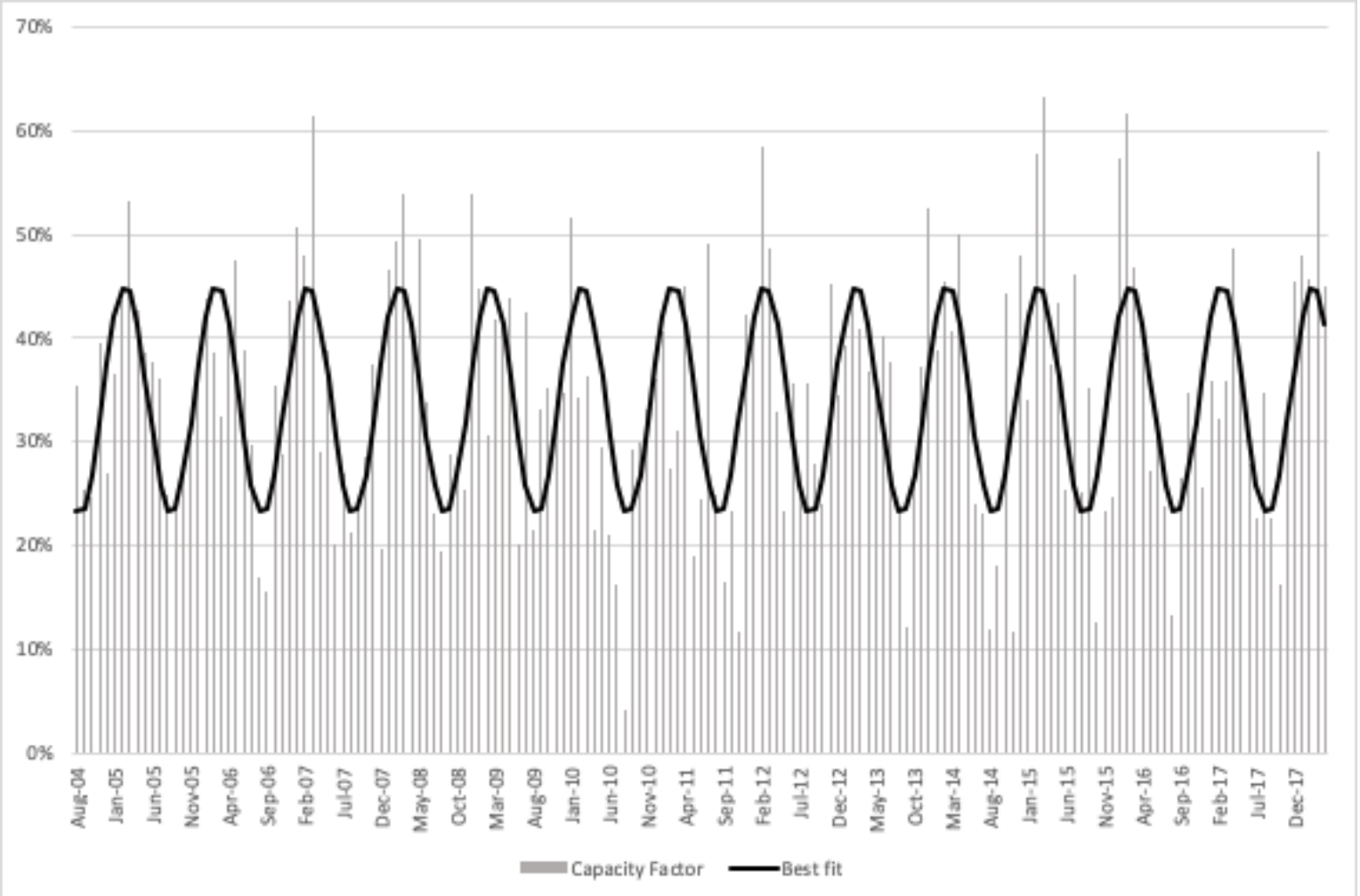

Figure 2: North Hoyle Monthly capacity factor and best fit sine curve, authors' analysis

A comparison of Figures 1 and 2 shows that intra-year variability in capacity factor is very much greater than the inter-year variability, and that there is a periodicity as autumns and winters are much windier than the summer period. The average annual capacity factor of North Hoyle is $36.2 \%$. In the winter periods (December-February), monthly capacity factors can exceed $60 \%$ but generally peaks at around 50\%. Similarly, in the summer (June - August), lows of around $20 \%$ are seen.

It is apparent that there is a seasonal periodicity in capacity factor, and this leads to the suggestion that a mathematical function could be fitted to model intra-year variability, should this be required for output modelling purposes. A sine wave has been selected as the most commonly used periodic function. Equation 2 shows a generalised formula for such a fitted curve.

$$
C F_{m}=A+B * \sin \left(\left(M_{m} / 12\right) * 2 * \pi+C\right)
$$

$\mathrm{CF}_{\mathrm{m}}=$ Capacity factor for month $\mathrm{m}$

$\mathrm{A}=$ annual mean capacity factor 
$\mathrm{B}=$ amplitude - variability range of capacity factor from mean

$\mathrm{C}=$ offset constant

$\sin =$ sine function with argument in radians

$\mathrm{M}_{\mathrm{m}}=$ index number of month $\mathrm{m}$, January $=1$, February $=2$ etc

The difference between the predicted and actual capacity factor has been evaluated for each month. Each error has been squared and the sum of the squares has been used as the objective function for optimisation. It is found that the sum of squared errors is minimised for values for A, B and C of $0.34,0.11$ and 7.642 respectively.

Inspection of this result suggests that the optimised curve does not fully reflect the random peaks and troughs, but rather smooths output over the year. While this optimised curve fitting can never capture all of the random variability of wind farm performance, it does provide a richer assessment of wind farm performance than a simple annual average and could be used in production forecasting when contracting for power offtake.

\subsection{Impact of capacity factor variability on LCOE}

LCOE is widely used as a measure of the lifetime cost of energy and is calculated as the discounted sum of costs divided by the discounted energy output, and given in $£ / M W h$ [35].

Probabilistic approaches are rarely used in evaluating renewable energy projects, although they are beginning to become more usual [31,36] . As Heck et al [31] say, "a Monte Carlo approach is only slightly more complex than using point values, but provides more realistic information about risk and uncertainty, and enables more useful analysis of potential investments in electricity generation".

However, in applying this approach, Heck et al. applied a capacity factor with a mean of $36.75 \%$ and a standard deviation of $7 \%$, thereby generating a wide range of possible LCOE for wind farms.

The foregoing analysis in this paper shows that a mean capacity factor (full life, Round 1 and 2 projects) of $38 \%$ and a standard deviation of $4.5 \%$ more accurately reflects UK offshore wind farms. Incorporation of these values in Heck et al.'s approach will clearly generate a lower LCOE (higher capacity factor produces more energy for the same cost) with a narrower range than the values obtained by Heck et al., with obvious potential impact on the perceived competitiveness of wind power. 
All of the Round 1-3 wind farms were developed with fixed foundations, comprising monopiles or jackets and secured to the seabed. As wind farms are deployed in deeper water, floating systems will be required, and some early trials of floating wind turbines have been deployed.

Equinor (formerly Statoil)'s HyWind floating wind farm demonstrator (30MW), comprising five 6.0 MW turbines offshore north-east Scotland, was installed near Peterhead in late 2017 and achieved full production in November that year. Equinor has claimed a capacity factor of "up to 65\%" [37]. The ROC data for HyWind has been analysed and confirms that claim.

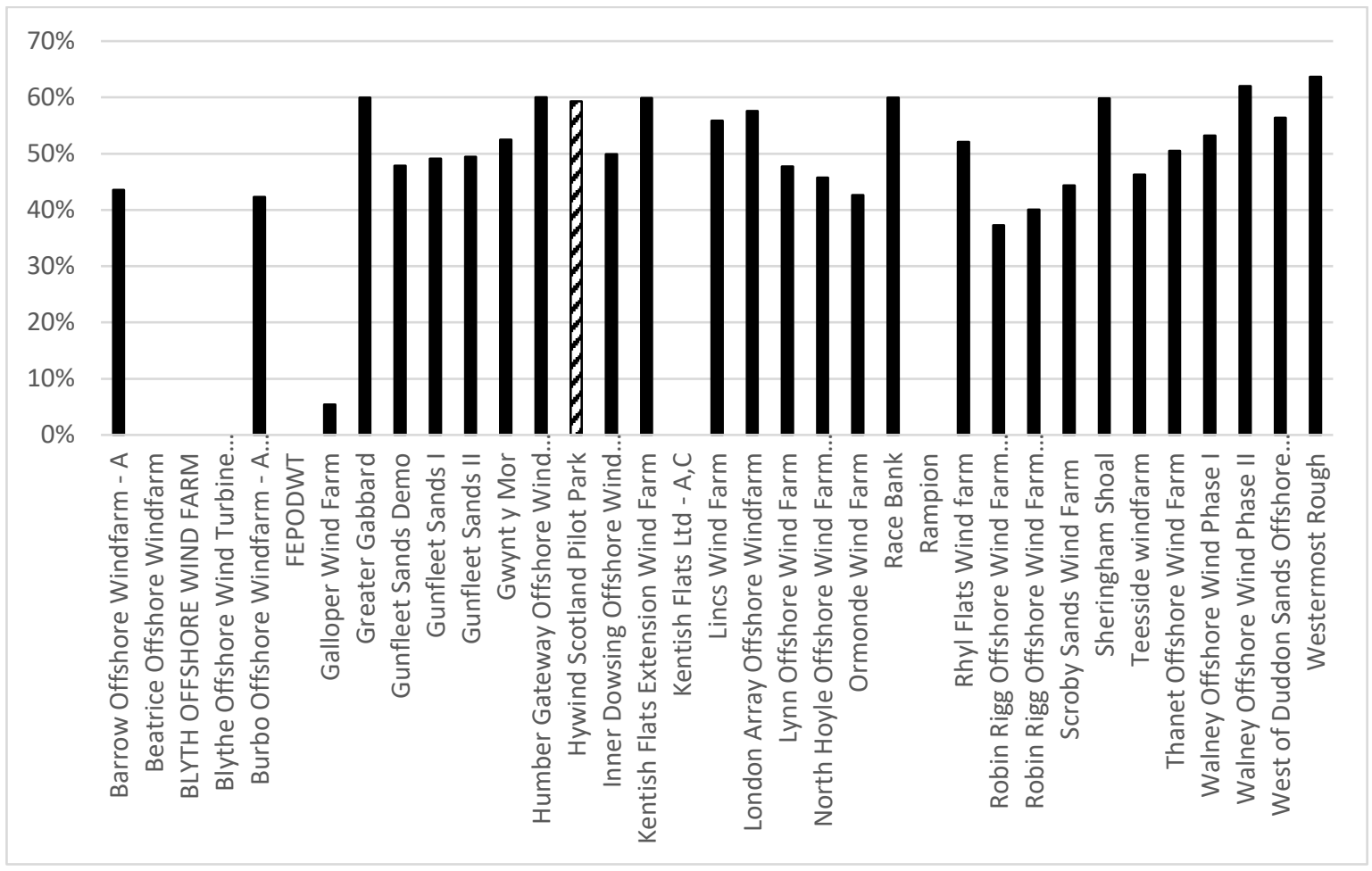

Figure 3: Capacity factor for the wind farm fleet, December 2017 (authors' analysis)

Figure 3 shows that Equinor's claim that bottom-mounted wind farms typically achieve capacity factors of $45-60 \%$ in winter is supported by a single month snapshot from December 2017, which also shows that the performance of the floating HyWind demonstrator is comparable with the best performing bottom-mounted wind farms, but not markedly better.

It may be worth noting that HyWind is situated further north and further offshore than any of the fixed wind farms currently operational in UK waters, and its higher capacity factor may simply be a reflection of the wind resource at this site. Further work will be required on the relative performance of floating and fixed as 
more data becomes available. Other floating wind farm projects include the Kincardine project offshore eastern Scotland (50MW), and Windfloat projects offshore Portugal (25MW) and Oregon in the United States (24MW). Additionally, as performance information from Beatrice and the Aberdeen "European Offshore Wind Deployment Centre" become available, more detailed and meaningful comparisons between fixed-foundation and floating wind projects will be possible.

\subsection{Spatial correlation across multiple wind farms}

This section considers how the performance of wind farms located close to one another is related, and how differences in performance can be interpreted. Figure 4 shows the location of the UK's offshore wind farms and shows that they can be divided into geographic groups.

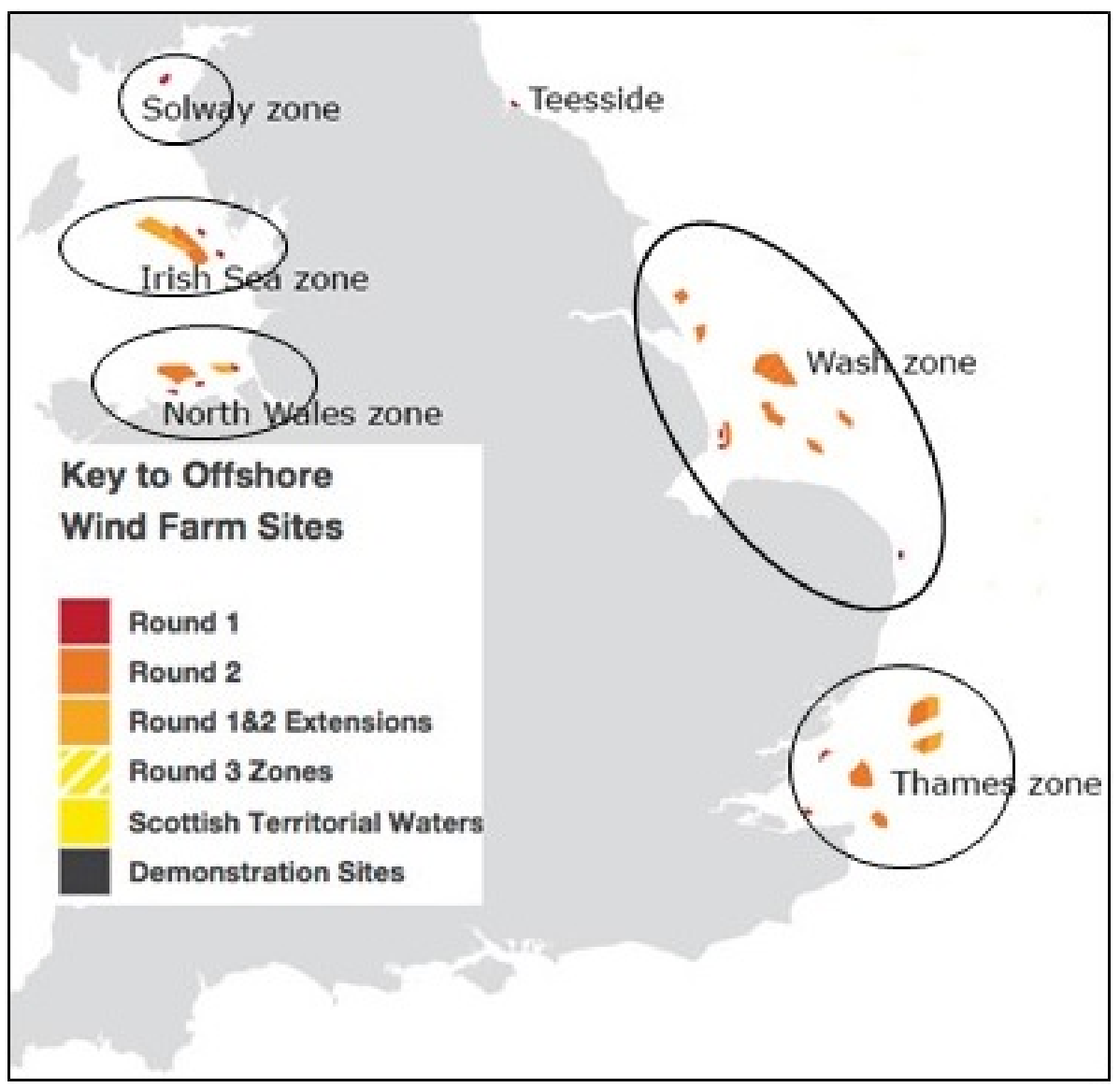

Figure 4: Map of UK Round 1 and 2 windfarms and authors' zones (modified from RenewableUK, 2016) Key: Irish Sea zone: Barrow, Burbo Bank, Ormonde, Walney I, Walney II, West of Duddon Sands; North Wales zone: Gwynt Y Mor, North Hoyle, Rhyl Flats; Solway zone: Robin Rigg (East), Robin Rigg (West); Thames zone: Greater Gabbard, Gunfleet Sands I and II, Kentish Flats and Extension, London Array, 
Thanet; Wash zone: Humber Gateway, Inner Dowsing, Lynn, Lincs, Scroby Sands, Sheringham Shoal.

Westermost Rough. The Teesside wind farm is in a group of one.

A statistical correlation coefficient between the capacity factor for each pair of UK offshore wind farms has been calculated and is organised geographically in Figure 5.

The correlation matrix (Figure 5) shows the correlations between and among the groups in the following order: Irish Sea, North Wales, Solway, Thames, the Wash and Teesside. It is clear that the Walney 2 wind farm is anomalous for the reasons stated in Section 4.4.

The correlation matrix confirms that the correlations within the geographic groups are somewhat stronger than between the groups (strong correlations are shown in green, and weaker correlations in red), although it should be noted that the groupings are somewhat arbitrary. It might be argued for example that the Wash Group could be divided into a northern zone - comprising Lynn, Inner Dowsing, Lincs, Humber and Westermost Rough) and a southern one of Scroby Sands and Sheringham Shoal.

Nonetheless, this analysis supports the suggestion that grouping wind farms into geographic zones in which performance is well correlated is supported by the data.

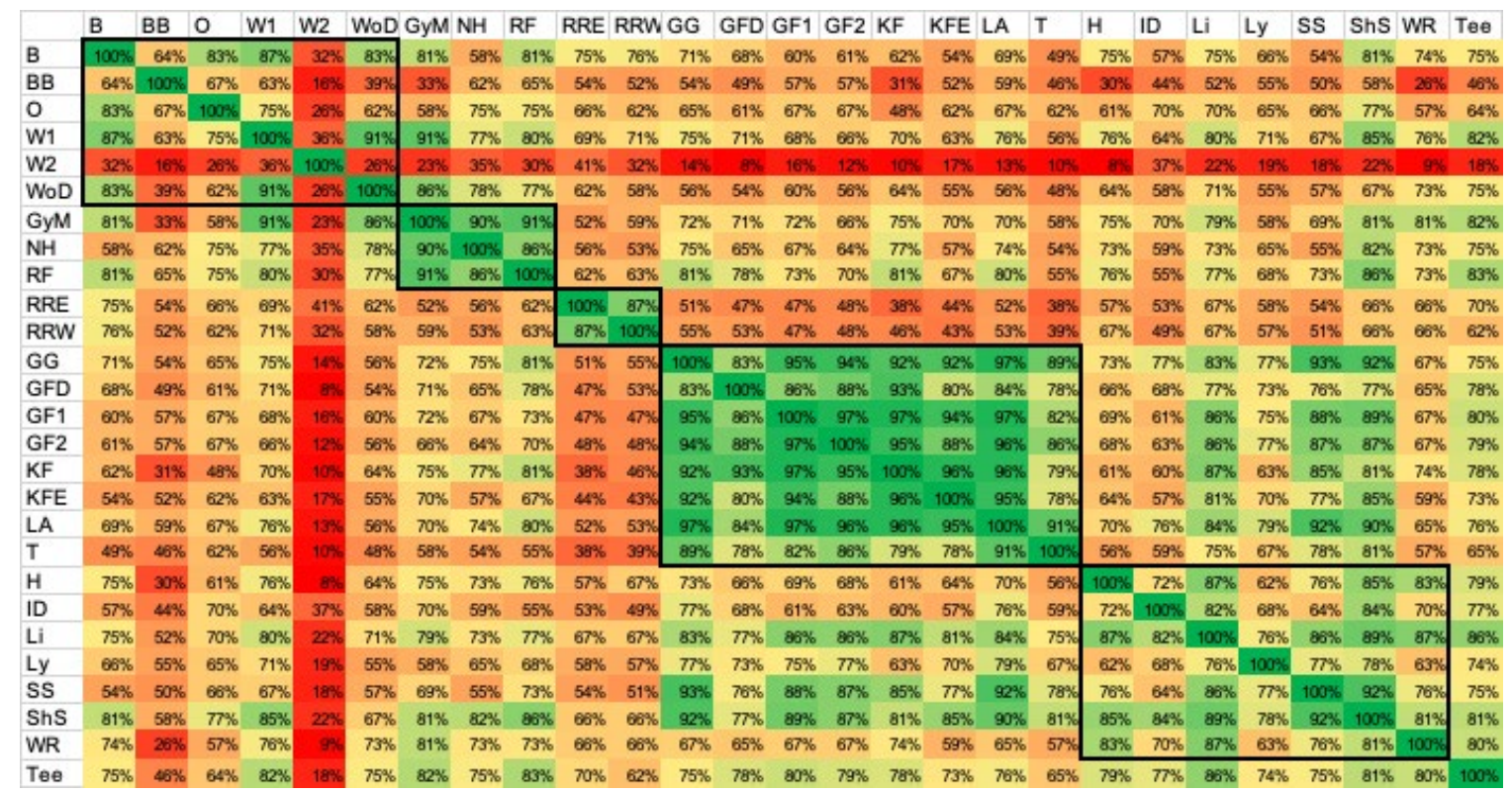

Figure 5: Correlation between wind farms (authors' analysis) (Key: B-Barrow, BB-Burbo Bank, O-Ormonde, W1-Walney 1, W2-Walney2, WoD-West of Duddon Sands, GyM-Gwynt y Mor, NH-North Hoyle, RF-Rhyl Flats, RRE-Robin Rigg East, RRW-Robin Rigg West, GG-Greater Gabbard, GFD-Gunfleet Sands Demo, GF1-Gunfleet Sands 1, GF2-Gunfleet Sands 2, 


\subsection{Analysing correlation between wind farms in a zone}

The quantitative calculation of correlation factors confirms the validity of the zones, but a more qualitative exploration of the performance of these wind farms throws more light on performance and reliability. A simple review of the "r-squared" correlation factor can identify but not explain a lack of correlation between nearby wind farms, while a qualitative review, based on graphical monthly performance information, can show why performance may not correlate.

As an example, Figure 6 shows the capacity factor for wind farms in the Irish Sea zone since the beginning of production. In general, there appears to be a strong correlation between the performance of the wind farms within the zone. The correlation breaks down when there are occasional short period downside events which affect only one windfarm in a zone, which can be inferred to be due to maintenance or unplanned outage.

This approach reveals the strong general correlation between these adjacent wind farms and allows easy identification of outages and other events which impacted production.

This comparative analysis approach could be used to analyse reliability and to identify differential performance trends. 


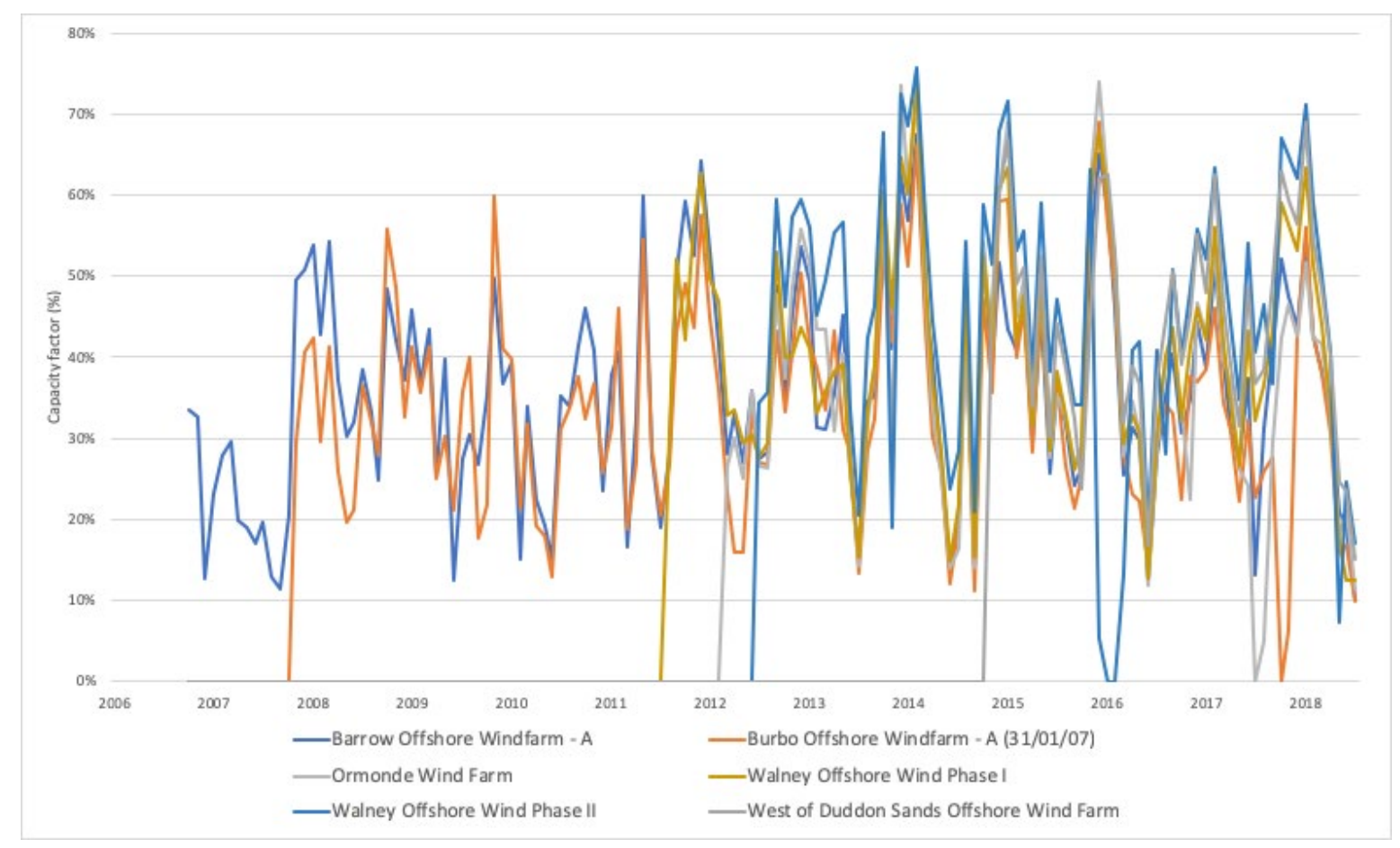

Figure 6: Performance of wind farms, Irish Sea zone (authors' analysis)

\section{Discussion and Conclusion}

While the effectiveness of the Renewables Obligation and other support schemes for renewables have been well reviewed in the literature, little advantage has been taken to date of the detailed performance information now available. We contend that the potential for policy-makers and project developers alike using this data to understand the detailed variability of wind farm performance is significant.

Capacity factor, and its variability, are important factors in the determination of LCOE. Government policies around the world rely on accurate estimation of LCOE in order to develop policies to support new renewable energy technologies. Policy design based upon flawed or inaccurate LCOE estimation would have serious implications for the future energy mix [38].

In addition, capacity factor is a critical determinant of the economic viability and value of wind farms. Wind farm capacity factor is driven by wind conditions, turbine power curves, turbine availability and wind farm wake effects. While wind condition data and turbine power curves are readily available, data on turbine and balance of plant availability is generally held as confidential by wind farm operators and turbine manufacturers, making the analysis of wind farm performance problematic. 
The overall availability of a wind farm is governed by the reliability of the wind turbines in the wind farm and ancillary equipment, together with factors regarding access and time to repair, and these figures are clearly commercially sensitive.

Estimation of output from wind speed information and power curves can give a theoretically-derived, but useful, indication of the maximum potential output from a single turbine. However, this predicted maximum output must be combined with actual or predicted outage and wake effect data to give a better indication of realistic actual output for a wind farm.

This paper extends an approach originally applied by Renewable Energy Foundation [10] to explore the details of offshore wind farm performance in the UK. This approach uses performance information from OFGEM's Renewables Register, which comprises detailed information on the actual month by month performance of ROC-accredited and other projects in the UK, and by definition takes into account the effect on output of reliability of the wind farm and wake effects, as well as the wind climate and the power curves. It was analysed to understand the true variability of wind farm performance for a number of UK wind farms.

This analysis shows that the performance of UK offshore wind correlates with water depth and age, confirming that more modern wind farms, which are typically further offshore than earlier projects, achieve higher capacity factors than those earlier projects. The year by year variability of capacity factor has been evaluated, allowing for improved probabilistic evaluation and better LCOE estimation.

The intra-year analysis shows the seasonality of variability in capacity factor for UK offshore wind farms and demonstrates that it is possible to fit a sine-based best fit curve to allow for broad prediction of month to month variability. This modelling could strengthen the operator's hand in negotiating power offtake arrangements, by providing a better forecast of power available in the more valuable winter months.

As floating wind farms become a more significant part of the electricity generation mix, their performance relative to fixed installations will become a subject for study. This analysis supports Equinor's claim that its HyWind project in Scotland achieves a capacity factor comparable to the best fixed offshore wind farms, although the northerly location of HyWind, offshore Peterhead in northeast Scotland may mean that the wind resource was better here than at other, more southerly sites for which data was available.

This paper also shows that there is a strong correlation in month by month performance between geographically grouped wind farms and variability in this correlation can give an insight into the impact on 
capacity factor caused by reliability issues in a wind farm. Further work in this area could produce quantified estimates of these impacts, and also provide general factors to convert theoretically-derived turbine capacity factors (from power curve and wind climate data) into expected wind farm output. This approach should be useful to policy makers, investors and wind farm developers, not just in the UK, but in other areas around the world.

Finally, it is noted that this approach may be employed anywhere detailed output data is available. Further work might consider analysis of wind farms in Denmark, Germany and Belgium and other locations where data is available.

\section{Acknowledgements}

Thanks are due to Judith Aldersey-Williams who provided critical insight and proof-reading. A number of anonymous reviewers provided valuable comments which have significant enhanced this paper. This work was undertaken as part of a PhD being undertaken at Robert Gordon University, Aberdeen, funded by Redfield Consulting Limited.

[1] GWEC. Offshore Wind - Global Wind 2016 Report. 2016; Available at: http://www.gwec.net/wpcontent/uploads/2017/05/Global-Offshore-2016-and-Beyond.pdf. Accessed 04/13, 2018.

[2] RenewableUK. UK Wind Energy Database home page. 2019; Available at: www.renewableuk.com/page/UKWEDhome. Accessed 08/19, 2019.

[3] Toke D. Scottish Electricity and Independence. In: Wood G, Baker K, editors. A Critical Review of Scottish Renewable and Low Carbon Energy Policy: Palgrave Macmillan; 2017. p. 199-209.

[4] Higgins P, Foley A. The evolution of offshore wind power in the United Kingdom. Renewable and Sustainable Energy Reviews 2014 September 2014;37:599-612.

[5] Andor M, Voss A. Optimal renewable-energy promotion: Capacity subsidies vs. generation subsidies. Resource and Energy Economics 2016 August 2016;45:144-158.

[6] Lipp J. Lessons for effective renewable electricity policy from Denmark, Germany and the United Kingdom. Energy Policy 2007 November 2007;35(11):5481-5495.

[7] Mitchell C, Bauknecht D, Connor PM. Effectiveness through risk reduction: a comparison of the renewable obligation in England and Wales and the feed-in system in Germany. Energy Policy 2006 February 2006;34(3):297-305.

[8] Nicolini M, Tavoni M. Are renewable energy subsidies effective? Evidence from Europe. Renewable and Sustainable Energy Reviews 2017 July 2017;74:412-423. 
[9] Otitoju A, Strachan P, Toke D. Assessing the performance of the UK Renewables Obligation: Cinderella or Ugly Sister? . In: Strachan P, Toke D, Lal D, editors. Wind Power and Power Politics: Routledge Ltd; 2009. p. 140.

[10] Renewable Energy Foundation. Renewable generators. 2018; Available at: http://www.ref.org.uk/generators/index.php. Accessed 03/08, 2018.

[11] Staffell I, Green R. How does wind farm performance decline with age? Renewable Energy 2014 June 2014;66:775-786.

[12] Crabtree CJ, Zappalá D, Hogg SI. Wind energy: UK experiences and offshore operational challenges. Proc Inst Mech Eng A: J Power Energy 2015 11/01; 2018/07;229(7):727-746.

[13] OFGEM. ROC Register. 2017; Available at: www.renewablesandchp.ofgem.gov.uk. Accessed March 7, 2017.

[14] RenewableUK. Development Rounds. 2018; Available at:

https://www.renewableuk.com/general/custom.asp?page=DevelopmentRounds. Accessed 08/14, 2018.

[15] 4C Offshore. 4C Offshore - Offshore Wind Farms. 2017; Available at: www.4coffshore.com/windfarms/. Accessed March 7, 2017.

[16] OFGEM. The Renewables Obligation: OFGEM's first annual report. 2004.

[17] HM Government Department for Trade and Industry. Reform of the Renewables Obligation. 2007.

[18] HM Government. Policy Paper: UK Energy Security. 2011.

[19] Khraiwish Dalabeeh AS. Techno-economic analysis of wind power generation for selected locations in Jordan. Renewable Energy 2017 2;101:1369-1378.

[20] Ayodele TR, Jimoh AA, Munda JL, Agee JT. Wind distribution and capacity factor estimation for wind turbines in the coastal region of South Africa. Energy Conversion and Management 2012;64:614-625.

[21] Chang T, Liu F, Ko H, Cheng S, Sun L, Kuo S. Comparative analysis on power curve models of wind turbine generator in estimating capacity factor. Energy 2014 8/14;73:88-95.

[22] García-Bustamante E, González-Rouco JF, Jiménez PA, Navarro J, Montávez JP. A comparison of methodologies for monthly wind energy estimation. Wind Energy 2009;12(7):640-659.

[23] Sinden G. Characteristics of the UK wind resource: Long-term patterns and relationship to electricity demand. Energy Policy 2007 1;35(1):112-127.

[24] Dvorak MJ, Archer CL, Jacobson MZ. California offshore wind energy potential. Renewable Energy 2010;35(6):1244-1254.

[25] Dvorak MJ, Corcoran BA, Ten Hoeve JE, McIntyre NG, Jacobson MZ. US East Coast offshore wind energy resources and their relationship to peak-time electricity demand. Wind Energy 2013;16(7):977-997.

[26] Masters GM. Renewable and efficient electric power systems. : John Wiley \& Sons; 2013.

[27] Jacobson MZ, Masters GM. Energy. Exploiting wind versus coal. Science 2001 Aug 24;293(5534):1438.

[28] Carroll J, McDonald A, McMillan D. Failure rate, repair time and unscheduled O\&M cost analysis of offshore wind turbines. Wind Energy 2016;19(6):1107-1119.

[29] National Statistics. Energy trends: weather. 2018; Available at: https://www.gov.uk/government/statistics/energy-trends-section-7-weather. Accessed 13/11, 2018.

[30] HM Government Department for Business, Energy and Industrial Strategy. Electricity Generation Costs. 2016.

[31] Heck N, Smith C, Hittinger E. A Monte Carlo approach to integrating uncertainty into the levelized cost of electricity. The Electricity Journal 2016 4;29(3):21-30. 
[32] Manzhos S. On the Choice of the Discount Rate and the Role of Financial Variables and Physical Parameters in Estimating the Levelized Cost of Energy. International Journal of Financial Studies 2013 Jan$1 ; 1(3): 54$.

[33] Partridge I. Cost comparisons for wind and thermal power generation. Energy Policy 2018;112:272-279.

[34] Cartelle Barros JJ, Lara Coira M, de la Cruz López,María Pilar, del Caño Gochi A. Probabilistic lifecycle cost analysis for renewable and non-renewable power plants. Energy 2016 10/1;112:774-787.

[35] Ebenhoch R, Matha D, Marathe S, Muñoz PC, Molins C. Comparative Levelized Cost of Energy Analysis. Energy Procedia 2015;80:108-122.

[36] Geissmann T. A probabilistic approach to the computation of the levelized cost of electricity. Energy 2017 4/1;124:372-381.

[37] Statoil. World class performance by world's first floating wind farm. 2018; Available at: https://www.statoil.com/en/news/15feb2018-world-class-performance.html. Accessed 03/03, 2018.

[38] Aldersey-Williams J, Broadbent ID, Strachan PA. Better estimates of LCOE from audited accounts - A new methodology with examples from United Kingdom offshore wind and CCGT. Energy Policy 2019 May 2019;128:25-35. 